\section{A MIMESE DE CONTEÚDO: ICONICIDADE NA POESIA LATINA E SUA TRADUZIBILIDADE}

\author{
Willamy Fernandes Gonçalves*
}

RESUMO: Neste artigo, apresentamos o uso expressivo da mimese de conteúdo em um trecho de Ovídio. Avaliamos diversas traduções poéticas do trecho para a língua portuguesa para verificar se os tradutores cuidaram da reprodução desse aspecto da poética latina, refletimos sobre as dificuldades que a mimese impõe para o tradutor lusófono e, por fim, oferecemos nossa tradução do trecho estudado.

PALAVRAS-CHAVE: Ovídio; mimese de conteúdo; tradução poética; História da tradução.

\section{THE MIMESIS OF CONTENT: ICONICITY IN LATIN POETRY AND TRANSLATABILITY}

* Membro do Grupo de Pesquisa Tradução e Recepção dos Clássicos, da Universidade Federal do Ceará. willamyfernandes@ gmail.com

\begin{abstract}
In this article, we present the expressive use of mimesis of content in an excerpt from Ovid. We evaluate several poetic translations of the passage into the Portuguese language to verify if the translators took care of the reproduction of this aspect of Latin poetics, we reflect on the difficulties that the mimesis imposes on the lusophone translator and, finally, offer our translation of the excerpt studied.
\end{abstract}

KEYWORDS: Ovid; mimese of content; poetic translation; History of translation. inda no século XIX, Schleiermacher (2001 [1813], p. 57) fez
a síntese dos dois grandes caminhos que se apresentavam
para o tradutor: ${ }^{1}$ trazer o autor traduzido para o mundo do
leitor ou levar o leitor para mais perto do mundo estrangeiro do
autor. Enquanto aquele primeiro caminho continuou assiduamente
frequentado, rendendo imensa quantidade de frutos (traduções
que aparam as arestas da língua-fonte e aplainam as dificuldades
do texto-fonte, produzindo textos que pudessem ser lidos como
literatura criada na própria língua alvo, tornando invisíveis as marcas

\footnotetext{
${ }^{1}$ Antes dele, a ideia já vinha se delineando entre pensadores de expressão alemã. Confira, por exemplo, os textos de Novalis, Goethe, Schlegel e Nietzsche em Heidermann (2001).
} 
do processo de tradução), o segundo caminho indicado pelo teórico alemão, permaneceu apenas como virtualidade, uma potencialidade raramente posta em ato, caminho escassamente frequentado por um ou outro desbravador solitário, campo tão fértil quanto incultivado.

Outro alemão, Walter Benjamin, num dos textos axiais para a história da teoria da tradução no Ocidente, $A$ tarefa do tradutor (Benjamin, 2001 [1923]), retoma a questão ao fazer a crítica da tendência geral dos tradutores ocidentais. Para Benjamin, ao focar na reprodução da mensagem ao invés de na reprodução da forma (a mensagem estética do poema), os tradutores ocidentais estariam fazendo a "reprodução inexata de um conteúdo inessencial" (Benjamin, 2001 [1923], p. 205). Ele, de certo modo, também estabelece uma teleologia da história da tradução, cujo papel principal seria o de acolher o impacto da língua estrangeira na língua-alvo ao invés de esconder do leitor o mundo estrangeiro da obra original. É célebre a citação de Pannwitz com que Benjamin (2001 [1923], p. 225) conclui suas reflexões:

Nossas traduções (mesmo as melhores) partem de um falso princípio, querem germanizar o sânscrito, o grego, o inglês, ao invés de sanscritizar, grecizar, anglicizar o alemão. Elas possuem um respeito muito maior diante dos próprios usos linguísticos do que diante do espírito da obra estrangeira [...] O erro fundamental de quem traduz é conservar o estado fortuito da sua própria língua, ao invés de deixarse abalar violentamente pela língua estrangeira.

A reflexão de Benjamin é contundente, mas permanece num nível abstrato. É Antoine Berman, tradutor francês, que, na sua obra O Albergue do Longínquo (2007), dá a expressão mais cabal a essa teorização, desdobrando-a e explicando-a passo a passo, mostrando concretamente como se realizam cada um dos dois caminhos, demonstrando a quase inexistência de frequentadores do segundo caminho ao longo da história da tradução no Ocidente e apontando suas aparições pontuais. Berman nos mostra como a figura dominante na prática tradutória do mundo ocidental é etnocêntrica (ao seguir aquele primeiro caminho apontado por Schleiermacher e Pannwitz), hipertextual (consequência natural do etnocentrismo e suas "tendências deformadoras", geradoras de opacidade que esconde o texto-fonte atrás de um novo texto, visto como um novo original. Essa hipertextualidade é algo inevitavelmente causado pela aplicação da cultura do tradutor e dos leitores ao textofonte, processo no qual "intervém massivamente a literatura", pois, para que "não se sinta uma tradução como tradução, tem-se que recorrer a procedimentos literários" (ao ter como pressuposto a existência autônoma do significado, que poderia, segundo essa concepção, ser separado do significante como a alma poderia ser separada do corpo e transmigrado, sem perdas, de um significante, a língua fonte, para outro significante, a língua-alvo).

A essa vertente dominante, Berman (2007) opõe o que chama de tradução ética, poética e pensante. Tradução ética é aquela que, ao contrário da etnocêntrica, respeita o "outro", evitando reduzi-lo ao "mesmo", aquela que "alberga o longínquo". Respeitar a letra

\footnotetext{
${ }^{2}$ Berman (2007, p. 34).
} 
significa levar em conta que é na relação entre significados e significantes que se encontra a poesia. O tradutor não fará mera operação mecânica ao transplantar o significado de uma língua a outra, pois significado e significante estão organicamente ligados: "transplantá-los" de uma língua a outra é sempre uma operação delicada que exige grande reflexão na tomada de decisões para separar aquilo que é funcional, e cuja manutenção é imprescindível, daquilo que pode ser sacrificado, visto serem os sacrifícios inevitáveis, e para se avaliar até onde se pode, por um lado, "violentar" o texto fonte e, por outro, a língua-alvo e qual o ponto ideal de equilíbrio entre atender as demandas da língua-fonte e/ou atender as demandas da língua-alvo.

Traduzir à letra não significa absolutamente traduzir palavra por palavra (tipo de tradução ainda estreitamente ligado àquela concepção que Berman chama "platônica"): como Benjamin (2001 [1923], p. 223) já havia dito, a "transparência" que permite a uma tradução revelar o original atrás de si é obtida antes pelo trabalho com a sintaxe e com os significantes. Na poética latina, o jogo com a sintaxe e a disposição espacial das palavras frequentemente é funcional, resultado da busca por uma iconização que atrela estreitamente significados e significantes. Berman (2007, p. 118), chega a tangenciar o tema ao analisar a Énéide de Klossowski:

No fundo, é o que Aristóteles enuncia na sua Poética: a arte "imita" a natureza, é mímesis. Mas se as relações das palavras entre si "mimetizam" o real sem nunca o "copiar", reordenando discursivamente, segundo as regras do francês, o dizer épico, perde-se sua substância mimética e icônica.

Porém, o teórico não se preocupa em detalhar seu ponto de vista, o que talvez explique o fato de que esse campo da sua teorização permaneça intocado por nossos tradutores.

No que diz respeito à poética latina, Berman vai somente até o ponto de perceber que o impacto da língua estrangeira na língua materna se dá sobretudo no âmbito da sintaxe. Ao falar da latinização do francês na Énéide de Klossowski, Berman (2007, p. 107-132), não sendo especialista em poética latina, restringe-se ao âmbito da poética mais geral e, tocando apenas na superfície da questão (Klossowski reproduz o "caráter fragmentado" ${ }^{3}$ da sintaxe poética latina), parece não perceber que o tradutor franco-polonês se esforça por reproduzir tudo aquilo que, no prefácio a sua tradução, chama "o teatro das palavras" da Eneida (apud Berman, 2007, p. 117):

Marmontel nota, com razão, que a epopeia não conta como a história, mas que ela imita uma ação.

O poema épico de Virgílio é, de fato, um teatro onde são as palavras que mimetizam os gestos e o estado de alma dos personagens, do mesmo modo que pelas suas posições, mimetizam também os acessórios próprios da ação.

\footnotetext{
${ }^{3} \operatorname{Berman}(2007$, p. 121).
} 
Esse "teatro das palavras" está longe de ser uma exclusividade da Eneida, ou de Virgílio: é característico da poesia latina, frequente não só em Virgílio mas também em Catulo, Propércio, Tibulo e Ovídio, dentre outros poetas. Vasconcellos (2008) nos apresenta uma pequena amostra de trechos desses poetas nos quais as palavras de certo modo fazem o que dizem, isto é, mimetizam, através da sua disposição no verso, o conteúdo que veiculam.

Aqui, apresentaremos um trecho das Metamorfoses de Ovídio (III, 420-429) e faremos a análise da sua "letra", apontando os referidos recursos poéticos. Apresentado o original, comentaremos sucintamente diferentes traduções que esse trecho recebeu no nosso idioma e verificaremos se os tradutores deram conta daqueles recursos. Por fim, apresentarei minha própria proposta de tradução poética do trecho referido.

A obra escolhida foi o episódio de Narciso, como contado nas Metamorfoses de Ovídio (Met. III, 420-429). A escolha do texto deve-se ao fato de que se trata de um dos épicos latinos mais revisitados por tradutores de língua portuguesa, de modo que, no momento de avaliar as traduções, tivemos ao nosso dispor um corpus razoável. O trecho específico (Met. III, 420-429) pareceu-nos muito apropriado por conta da sua riqueza em figuras de elocutio, ligadas à disposição das palavras nos versos. Também motivou nossa escolha o fato de que, nesse trecho, inclusive a temática dá relevância à visualidade, em contraposição à relevância dada ao som e à audição no trecho que o precede no livro de Ovídio: lá, Narciso confundira-se com o eco (reflexo da sua voz), aqui, com sua imagem refletida na água. Não à toa Ovídio enriquece esse trecho com recursos de mimese do conteúdo, o que não deveria ser ignorado pelo tradutor.

Passemos ao trecho de Ovídio, que flagra o momento em que Narciso apaixona-se por si mesmo:

Spectat humi positus geminum, sua lumina, sidus et dignos Baccho, dignos et Apolline crines inpubesque genas et eburnea colla decusque oris et in niveo mixtum candore ruborem, cunctaque miratur, quibus est mirabilis ipse: se cupit inprudens et, qui probat, ipse probatur, dumque petit, petitur, pariterque accendit et ardet. inrita fallaci quotiens dedit oscula fonti, in mediis quotiens visum captantia collum bracchia mersit aquis nec se deprendit in illis!
Contempla, deitado na terra, gêmeos astros, seus lumes, e, dignos de Baco, dignos também de Apolo, os cabelos, imberbes faces e ebúrneo colo, a bela boca e, misturado à nívea candura, o rubor. Tudo admira, pelo que é admirado ele próprio, deseja a si mesmo, ignorante, e quem aprova é ele mesmo aprovado Quando busca é buscado, ao mesmo tempo acende e arde. Quantas vezes vãos beijos deu à falaz fonte! Quantas vezes, em meio às águas mergulhou os braços que buscavam capturar o visto colo, e não conseguiu apanhar-se nelas! ${ }^{4}$

Comecemos o exame da elocutio pelo verso 423: oris et in niveo mixtum candore ruborem. Escandindo o hexâmetro de Ovídio, veremos que a palavra mixtum ocupa nele a posição central, destacada entre as pausas triemímera e pentemímera:

$$
\text { oris et // in niue // o } \mathbf{T} \text { mix // tum } \mathbf{P} \text { can // dore ru // borem }
$$

\footnotetext{
${ }^{4}$ Tradução nossa. De início, fornecemos, propositadamente, essa tradução em prosa.
} 
A posição de destaque em que Ovídio coloca esse adjetivo, serve de indicador para nos fazer prestar atenção ao jogo de palavras no verso: o poeta ilustra a mistura de que está falando (de tons vermelhos e brancos em Narciso) com a própria disposição das palavras. Ele mistura os sintagmas niveo candore ("nívea brancura") e "mixtum ruborem" ("rubor misturado"), colocando os dois adjetivos à esquerda e os respectivos substantivos à direita, criando a estrutura, abAB (variante do verso áureo, do qual falaremos abaixo), fazendo assim uma mimese de conteúdo, ou seja, colocando a própria disposição das palavras para mimetizar o conteúdo que veiculam. Ainda podemos associar o ruborem à boca (oris) ficando os dois elementos vermelhos nos extremos do verso, enquanto niveo candore fica mais próximo do centro. Ovídio faz tudo isso sem descuidar do plano sonoro do verso, rico em paronomásias: oris et in niveo mixtum candore ruborem.

No verso seguinte, podemos ver uma estrutura espelhada, refletindo na forma do verso a cena que descreve: cunctaque miratur, quibus est mirabilis ipse. Ovídio destaca a expressão quibus est (que podemos traduzir como "pelo que", "através do que") entre as pausas pentemímera e heftemímera:

cunctaque // mira // tur, $\mathbf{P}$ quibus // est $\mathbf{H}$ mi // rabilis // ipse.

A expressão tem duas palavras à sua direita e outras duas à sua esquerda. Se a tomarmos como centro do verso (o espelho d'água), de um lado teremos o miratur (“admira”), do outro lado, na posição espelhada correspondente, teremos mirabilis ("admirado") e, nos extremos, cuncta ("tudo") e ipse ("si mesmo"). Desse modo, Ovídio já antecipa o erro de Narciso: tomar a si mesmo como tudo o que importa, o que o levará à morte nos versos posteriores.

No verso 427, não temos exatamente uma mimese de conteúdo, mas um efeito ornamental muito valorizado entre os poetas romanos, como indica seu próprio nome, o 'verso áureo': inrita fallaci quotiens dedit oscula fonti. Na ordem direta, teríamos “quotiens inrita oscula fallaci fonti dedit", com os pares adjetivo-substantivo reunidos. No verso áureo, esses dois sintagmas nominais são quebrados e redistribuídos: os adjetivos são colocados juntos a um lado, os substantivos são colocados, juntos, do outro lado, ficando o verbo a separar esses dois novos pares. Com essa disposição, o poeta consegue enfatizar o paralelismo entre os dois sintagmas, tornando mais forte o contraste ou a semelhança entre as qualificações dos dois substantivos.

Para encerrar nossa análise do trecho, falemos dos versos mais interessantes, os dois últimos do trecho selecionado:

\section{in mediis quotiens visum captantia collum \\ bracchia mersit aquis nec se deprendit in illis!}

Nesses dois versos está uma das mais belas façanhas do poeta. Ovídio consegue engendrar aqui uma dupla mimese de conteúdo. Nos versos, há duas orações, coordenadas pela conjunção nec. Narciso, tentando abraçar o pescoço visto (collum uisum), mergulhou (mersit) seus braços "agarrantes" (bracchia captantia) em meio às águas (in mediis aquis). Ovídio dispõe as palavras de modo que mediis e aquis ficam separadas nos dois extremos da oração, 
todo o restante, o collum uisum e os bracchia captantia (Narciso abraçando o reflexo), fica, de fato, "no meio das águas". Mas o poeta não parou por aí. Foquemos agora no que ficou no meio: Ovídio faz que Narciso abrace o reflexo não só no conteúdo, mas igualmente na forma, na disposição das palavras, ficando bracchia captantia e visum collum entrelaçados numa estrutura abAB (em que as letras minúsculas representam os adjetivos e as letras maiúsculas representam os substantivos com os quais concordam), que iconiza o abraço.

\section{As TRADUÇÕES}

Feita a análise do original, vejamos de que modo os elementos apontados foram tratados por nossos tradutores. Como resultado de nossas buscas, encontramos sete traduções que contemplam o trecho: duas traduções setecentistas, pelos poetas árcades Almeno (Ovídio, 1805) e Cândido Lusitano (Predebon, 2006); uma tradução oitocentista, pelo poeta e tradutor romântico António Feliciano de Castilho (Ovídio, 1841); uma tradução do século XX, por David Gomes Jardim Jr. (Ovídio, 1983); por fim, três traduções da primeira década do nosso século: Haroldo de Campos (Campos, 2004), Paulo Farmhouse Alberto (Ovídio, 2007) e Raimundo Carvalho (Carvalho, 2010).

É preciso salientar que as traduções que veremos abaixo têm objetivos diversos, não necessariamente ligados à reprodução das mimeses de conteúdo. Nossa avaliação, contudo, restringe-se a esse aspecto, de modo que não se deve tomá-la como uma avaliação geral da qualidade dessas traduções.

\section{As TRADUÇõES DO SÉCULO XVIII: ALMENO E CÂNDIDO LUSITANO (1805 E 1771)}

Almeno
$\qquad \ldots]$ Estendido
No chão, contempla os olhos seus dois astros,
E as tranças quais de Baco, quais de Febo,
O colo de marfim, sem velo as faces,
A boca linda, a cor de branco lírio
Com rosa misturado: e admira tudo,
Que admirável o faz. E loucamente
Por si perdido, louva, e é louvado:
É requestado ao tempo, que requesta:
De volta acende e arde. Quantas vezes
Beijou em vão a mentirosa fonte:
Quantas vezes no meio d'água os braços,
Apanhando, mergulha, o visto colo,
E nem se colhe neles! [... $]^{5}$

Almeno

Cândido Lusitano

\footnotetext{
${ }^{5}$ Não colocamos aqui o texto latino de Ovídio (1805, p. 160). Fizemos a atualização ortográfica do trecho, mas evitamos modificar a pontuação de Almeno.

${ }^{6}$ Utilizamos a edição de Predebon (2006, p. 270).
} 
Ambas as traduções perdem aqueles efeitos que analisamos acima. O próprio ideal arcádico de clareza (em contraposição aos obscuros barroquismos do período literário precedente) dificulta a fidelidade da tradução a tal aspecto da poética latina. A ordem direta da língua portuguesa desfaz todo o tecido sintático latino, destruindo o seu efeito fragmentário. Por isso Berman (2007, p. 121-122) nos fala da necessidade de o tradutor trabalhar nas zonas não normatizadas da sua língua, pois é aí que ele poderá alargar as suas possibilidades de expressão, aproximando-a da língua estrangeira. Os neoclássicos do século XVIII caminham na contramão dessa sugestão: seu ideal de manutenção de um português castiço (sempre embasado nos clássicos quinhentistas, que estabeleceram o padrão de "portuguesidade") os mantém presos nos limites desse "muro da sintaxe".

O verso decassílabo, demasiado estreito para a tradução do verso épico latino, força os tradutores a abrir mão da equivalência do número e da ordem dos versos entre tradução e original (a isostiquia ${ }^{7}$ e, assim, muda a distribuição dos versos. Veja-se como exemplo o verso 423 que, nessas duas traduções, foi distribuído por duas linhas, dificultando a reprodução do efeito icônico. O mesmo vale para o verso 424 na tradução de Almeno. Em ambas as traduções não restou nenhum vestígio do verso áureo: Almeno transformou oscula dedit (substantivo + verbo) num verbo e também o adjetivo inrita numa locução adverbial, "em vão". Por sua vez, Cândido Lusitano, com liberdade ainda maior, substituiu oscula por "fronte" e dedit por "aproximou". Ainda que seja uma tradução semanticamente mais livre, ao contrário de Almeno, ele mantém adjetivo e substantivo, no entanto não faz sentido qualificar a fronte de "vã" para traduzir inrita, de modo que o tradutor se vê obrigado a operar a mesma transformação feita por Almeno, traduzindo o adjetivo por uma locução adverbial.

Nos dois últimos versos (transformados em dois e meio nas duas traduções) tampouco se conserva a iconicidade. Almeno, ainda que fazendo uma tradução praticamente palavra por palavra, não é fiel à letra naquele sentido bermaniano. Cândido Lusitano, muito mais livre, perde não só a elocutio original, mas também termos importantes ao traduzir bracchia captantia por "níveos braços" e mediis aquis por "corrente", o que traz ressonâncias semânticas não exatamente presentes no original (corrente que manterá Narciso preso e terminará por causar sua morte), sendo uma das marcas da intervenção literária do tradutor.

\section{SÉCULO XIX: A TRADUÇÃo DE ANTÓNIO FELICIANO DE CASTILHO (1841)}

Debruçado, contempla aqueles olhos,

Astros seus; alvas mãos dignas de Baco;

Madeixas, que às de Apolo em nada invejam;

Faces imberbes, colo ebúrneo, boca

Linda, estreita, no lírio a cor das rosas:

Admira tudo enfim, que admiram nele.

Louco por si, recebe os seus louvores;

\footnotetext{
${ }^{7}$ Cf. Guerini; Costa. "Entrevista com João Angelo Oliva Neto". Cadernos de Tradução, UFSC, v. 1 , n. $25,2010$.
} 
Arde, inflama; requesta, é requestado.

Que beijos vãos nas águas mentirosas!

Que abraços dentro nelas malogrados!

As traduções do poeta romântico Feliciano de Castilho são em alguns casos por ele mesmo classificadas como "versão libérrima"8 ou "paráfrase", 9 mais do que propriamente traduções. Para a sua tradução das Metamorfoses, no entanto já no prólogo, Feliciano de Castilho anuncia "quanto diligenciei manter intacto o meu voto de profissão de tradutor leal" (Ovídio, trad. Castilho, 1841, p. XV) logo depois de definir os seus procedimentos (p. XIV):

Encontrei muito luxo, que importaria podar, e abstive-me: algumas vezes vi rareiras desaproveitadas onde me não houvera sido muito difícil semear mais poesia; e também me abstive: dei com muita formosa desnudez [o] que, em obra minha, houvera vestido ou, quando menos, velado, e deixei-as, tendo para mim, como já para si tivera o religioso e missionário Almeno, que em obras de tal vulto e antiguidade não era permitido fazer tais reformações. ${ }^{10}$

O trecho acima mostra que Feliciano buscou evitar a hipertextualidade consciente. Quando avaliamos os acréscimos e deslocamentos semânticos que destacamos no texto da sua tradução pelos padrões de fidelidade dos teóricos em que estamos nos baseando, podemos chegar à conclusão de que Castilho não teria cumprido o prometido. Contudo, a sua concepção de fidelidade explica a aparente contradição (Ovídio, trad. Castilho, 1841, p. XIII):

Entendi, portanto, que era dever meu fazer o mesmo que o meu Autor, sem nenhuma falta, haveria feito, se em meu lugar e tempo houvera escrito. [...] em todos os lances, em que se me antolhou, que um curioso de meã leitura poderia ficar embaraçado, ora ladeei e me desviei, sem fugir, ora acrescentei uma penada que desfizesse a dúvida. [...] Finalmente, não são as palavras, as que se bão de verter, mas os pensamentos, conceitos, e afetos. [...] O vosso Autor só procurou, e escolheu vocábulos, e frases, em sua língua, para lograr este fim; se outro tanto fizestes na vossa e outro tanto conseguistes, fizestes tanto e tão bem, senão melhor, e muito mais façanha do que ele.

A pretensão romântica que já tinha aparecido no trecho anterior repete-se aqui. Não só no considerar "fazer maior façanha que ele [o autor do original]", mas no acreditar poder julgar o que o autor escreveria se seu instrumento fosse a língua portuguesa ao invés

\footnotetext{
${ }^{8}$ Confira a sua tradução da comédia de Molière: As sabichonas, comédia em 5 atos: versão libérrima (Castilho, 1872).

${ }^{9}$ Confira a sua tradução dos Amores de Ovídio: Os Amores, de P. Ovidio Nasão: paraphrase, por Antonio Feliciano de Castilho (1858). Em sua folha de rosto, é ainda designada como "traducção paraphrastica". ${ }^{10}$ Citamos da edição de 1841, mas fizemos a atualização ortográfica e padronizamos a pontuação de acordo com o uso atual.
} 
da latina. Toda a superior potência criativa que o poeta-tradutor alardeia repetidamente (e a que ele deu livre curso em suas traduções anteriores) dizendo-a refreada pelo fato de que aqui ele não é autor, mas tradutor, encontra vazão (e sublimação) nessa brecha com que Castilho justifica suas infidelidades. O etnocentrismo, a hipertextualidade e o platonismo (naquele sentido bermaniano) de sua concepção de tradução ficam claramente explicitados nos dois trechos que citamos.

Castilho perdeu também aqueles efeitos de que tratamos. Quanto ao verso 423, cabe destacar a extrema liberdade com que foi traduzido, de modo que a opacidade da tradução a põe como um hipertexto interposto entre o leitor e o texto de Ovídio. No verso 427, destacamos a tradução quase palavra por palavra, com exceção do "que" com que traduz quotiens: enquanto o termo latino tem sentido quantitativo, o termo português tem sentido qualitativo. Também é notável que, ao passo em que os setecentistas transformaram em três os versos 428 e 429, Castilho os reduz a um só e perde completamente a dupla mimese de conteúdo.

SÉCULO XX: A TRADUÇÃO DE DAVID GOMES JARDIM JR. (1983)

Deitado no chão, contempla dois astros, seus olhos, os cabelos dignos de Baco e de Apolo, o rosto imberbe, o pescoço ebúrneo, a linda boca e o rubor que cobre a cútis branca como a neve. Admira tudo, pelo que é admirado ele próprio, deseja a si mesmo, em sua ignorância, e, louvando, é a si mesmo que louva. Inspira a paixão que sente, e, ao mesmo tempo, acende e arde. Quantas vezes beijou em vão a água enganosa! Quantas vezes, para abraçar o pescoço que via, mergulhou os braços na água, sem conseguir abraçar-se!

Apesar de estarmos estudando aqui a tradução de recursos poéticos, não repudiamos apresentar uma tradução em prosa, pois a forma do conteúdo e o cuidado na escolha das palavras (levando em conta tanto os jogos semânticos quanto as figuras de repetição de sons ou morfemas) poderiam ter sido mantidos mesmo em prosa mais facilmente até do que numa tradução poética, que tem que lidar com as restrições da métrica. Além disso, ainda que o próprio formato do texto em prosa, sua disposição num bloco compacto, não favoreça a apreensão de jogos visuais (dentre outros motivos, por não colocá-lo no horizonte de expectativa dos leitores), a reprodução dos recursos visuais, dos recursos relacionados à colocação das palavras, também é possível numa tradução em prosa (como comprova, por exemplo, a cuidadosa tradução filológica da Eneida por Bellessort). ${ }^{11}$

\footnotetext{
${ }^{11}$ Virgile, em edição de 1961.
} 
Mas o que temos aqui é uma tradução interessada apenas em manter o conteúdo mais geral $^{12}$ do texto. Mais do que uma tradução, o texto se torna uma paráfrase interpretativa, ${ }^{13}$ e a ele se aplicam as palavras de Vasconcellos (2011, p. 69):

Tenho a impressão de que, por vício da tarefa ancestral de explicação dos textos, tendemos por vezes a traduzir escolhendo palavras e expressões que acabam criando como que uma versão simplificadora de tudo que o original possa ter de difícil, enigmático, impreciso, vago.

Por razões que não convém expor aqui, parece-nos provável que, apesar de não haver nenhuma advertência da editora a respeito, esta seja uma tradução indireta, sendo esse, possivelmente, um dos motivos pelos quais ela não captou os recursos que estudamos.

\section{SÉCULO XXI: AS TRADUÇÕES DE HAROLDO DE CAMPOS, PAULO FARMHOUSE ALBERTO E RAIMUNDO DE CARVALHO}

Só na primeira década do século XXI, tivemos várias traduções parciais e pelo menos uma tradução integral do épico ovidiano para a língua portuguesa. Essa produtividade reflete sem dúvida o grande salto que a teoria da tradução efetuou ao longo do século XX, tornando evidente a necessidade das retraduções e da convivência de múltiplas concepções de tradução. Uma tradução totalizante, que abarcasse todos os aspectos do original, é algo utópico, cada tradução busca a seu modo captar determinada característica formal do original: a constante retradução de uma obra é parte do que a mantém viva e, nisso, a tradução aproxima-se da crítica e da tradição gerada pela obra original, a sua hipertextualidade. Alcançar o objetivo da tradução totalizante talvez representasse a morte da obra, o selo e a campa de sua tradição.

Veremos, no entanto, que os tradutores em geral não focam sua atenção nos aspectos visuais da poesia latina, e esse permanece um ângulo inexplorado da grandeza inesgotável desses poemas.

\section{A TRADUÇão de HAROLdo de CAMPOS (2004)}

Haroldo de Campos é um poeta estreitamente ligado à estética concretista e, além disso, é o teórico da tradução mais influente no Brasil atualmente, tanto por sua obra críticoteórica, quanto por sua obra tradutória (indissociável da primeira). Sua teoria da transcriação, influenciada por Walter Benjamin, aproxima-se em muitos pontos da teorização de Antoine Berman e tem como ponto chave seguir a ideia jakobsoniana de que, na poesia, a forma do conteúdo é o principal determinador na construção do significado, indo na contramão da tendência histórica do Ocidente. Por outro lado, como seu próprio nome indica, o papel

\footnotetext{
${ }^{12}$ Falo de "conteúdo mais geral", pois é difícil separar forma e conteúdo em poesia: o conteúdo mais sutil é veiculado pela forma.

${ }^{13}$ Cf. Berman (2007), especialmente o capítulo que cataloga as "tendências deformadoras" da tradução.
} 
criador do tradutor ganha relevo em sua teoria, o que torna suas traduções hipertextuais por definição:

Contempla seus cabelos dignos de Apolo
ou de Baco; suas faces, seu pescoço branco,
a elegância da boca; a tez, neve e rubor.
No mirar-se, admira o que nele admiram.
Deseja-se a si próprio, a si mesmo se louva,
Súplice e suplicado, ateia o fogo e arde.
Quantos beijos vazios deu na mentira d'água!
Quantas vezes tentou captar o simulacro
e mergulhou os braços abraçando nada!

Sua tradução é bastante livre quanto à reprodução do desenho sintático e pouco interessada na manutenção das mimeses de conteúdo. Apenas merece ser mencionado que, no verso 427, ele mantém o "modo de visar" do original, evitando transformar o substantivo "beijos" no verbo "beijou". Nos versos 428 e 429, perde a dupla mimese de conteúdo, inclusive deixando de reproduzir vários dos seus constituintes.

Quando publicou sua tradução do primeiro canto da Iliada, Haroldo (Campos, 1994, p. 14) expôs as diretrizes do seu projeto tradutório de Homero, que se aplica a sua tradução de Ovídio:

Estou empenhado em recriar, em nossa língua, quanto possível, a forma de expressão (no plano fônico e rítmico-prosódico) e a forma do conteúdo (a "logopeia", o desenho sintático, a "poesia da gramática") [...] Estou persuadido [...] de que do "transcriador da rapsódia homérica se requer, no plano da fatura poética, uma atenção micrológica à elaboração poética de cada verso (paronomásias, aliterações, ecos, onomatopeias), aliada a uma precisa técnica de cortes, remessas e encadeamentos frásicos).

Apesar de ter traduzido também latinos (sobretudo Catulo), sempre que teoriza sobre a tradução de autores clássicos, Haroldo de Campos fala especificamente de poetas gregos (todos anteriores ao período helenístico, no qual os poetas já tinham assimilado o impacto da escrita para a produção poética) e parece nunca ter considerado necessária uma reflexão especificamente dirigida aos poetas do Lácio. Da nossa análise de suas traduções, depreendemos que ele aplicou os mesmos critérios, expostos acima, indiscriminadamente a gregos e romanos.

É sugestivo o fato de Haroldo considerar o "desenho sintático" como da ordem da forma do conteído. No entanto, quando discrimina os elementos aos quais dedicaria sua "atenção micrológica" (Campos, 1994, p. 14), lista somente elementos do plano sonoro: essa preferência, como vimos, transparece na sua tradução. 


\section{A tradução de paulo farmhouse alberto (2007)}

Estendido no chão, contempla seus olhos, astros gêmeos, e os cabelos dignos de $\mathrm{Baco}$, dignos até do próprio Apolo, as faces impúberes e o pescoço de marfim, e o esplendor dos lábios, e o rubor misturado com a alvura da neve.

Olha maravilhado para tudo o que o torna maravilhoso. Sem saber, deseja-se a si próprio, e o elogiado é quem elogia; e, ao desejar, é o desejado, e junto incendeia e arde de amor. Quantas vezes beijos vãos não deu aquela fonte enganadora! Quantas vezes não mergulhou os braços no meio das águas para abraçar o pescoço que vê, e não se abraçou a si mesmo!

Paulo Farmhouse Alberto é professor da Faculdade de Letras da Universidade de Lisboa e se insere numa tendência atual, em Portugal, das traduções de clássicos greco-latinos: trata-se de uma tradução em versos livres com isostiquia. ${ }^{14}$ Por conta dos versos demasiado longos (a maioria tem entre 17 e 19 sílabas) a tradução tem o efeito de ser confundível com prosa.

A liberdade quanto ao metro facilitaria a reprodução daqueles jogos poéticos do original, porém, já ao ler os critérios de tradução (Alberto, 2007, p. 27-28), percebemos que não estava entre as intenções do tradutor a manutenção dos aspectos que estamos estudando neste artigo:

A presente tradução destina-se ao leitor que não tem o privilégio
de ler Ovídio no original (ou, pelo menos, com a desenvoltura
necessária), mas que tem gosto poético e aprecia uma boa história
bem contada. Procura em linguagem simples e direta, seguir fielmente
o texto latino [...] de modo que se possam apreciar as imagens,
os jogos de sentido, as metáforas, o registo apropriado, por vezes
mesmo o ritmo do texto ovidiano [...]. Mesmo no caso de certas
repetições de palavras, características do estilo ovidiano, que em
português nem sempre são de bom gosto [...] preferi mantê-las,
justamente por uma questão de fidelidade ao estilo ovidiano.

Verificamos que Farmhouse, na contramão da concepção benjaminiana de tradução literária, leva em consideração um público específico (um público leigo, mas culto, pelo que se deduz das palavras acima) e valoriza sobretudo a manutenção do sentido. Ao procurar contar as histórias "em linguagem simples e direta", o tradutor aproxima-se daquele "didatismo" que já evocamos ao comentar a tradução de David Gomes Jardim Jr. Porém, com muito maior sensibilidade literária do que este último, Farmhouse procura manter "as imagens,

\footnotetext{
${ }^{14}$ Seguem essa mesma tendência as traduções da Ilíada e da Odisseia por Frederico Lourenço, o Da Natureza das Coisas, poema de Lucrécio, por Luís Manuel Gaspar Cerqueira e as já citadas traduções de Carlos Ascenso André, Amores e Arte de amar, de Ovídio.
} 
os jogos de sentido, as metáforas, o registo apropriado, por vezes mesmo o ritmo do texto ovidiano" e uma certa "fidelidade ao estilo ovidiano" (embora limitada a alguns aspectos específicos, como vimos).

Passemos a um breve exame de sua tradução. No verso 423, Farmhouse manteve o mixtum na posição central, mas reagrupou os sintagmas dispersos (misturados) e colocou tudo bem separado: "lábios", "rubor" e "misturado" à esquerda, "alvura" e "neve" à direita. No verso 424, modifica consideravelmente o modo de visar (die Art des Meinens) ${ }^{15}$ do original, perdendo totalmente o efeito mimético de espelhamento do verso. No verso 427 , operou reagrupamento similar àquele do verso 423 , reintegrando os pares substantivo/adjetivo e perdendo o verso áureo e seu efeito de paralelismo. Por fim, nos dois últimos versos, inverteu completamente a relação posicional na primeira oração, colocando "no meio das águas" (mediis... aquis) na posição central, cercada pelos "braços" de um lado e "o pescoço que vê" do outro, e ainda perdeu o adjetivo ligado ao bracchia no original, captantia, definitivamente ignorando as mimeses de conteúdo.

Farmhouse ignora as mimeses de conteúdo e o verso áureo. A própria proposta de sua tradução torna difícil a reprodução desses recursos, que geralmente exigem certo contorcionismo sintático. Se o tradutor buscasse um texto facilmente legível ao longo dos versos que não exploram esses recursos de disposição das palavras, mas ao mesmo tempo quisesse preservá-los quando aparecem, sempre que se deparasse com algum desses recursos, seria forçado a usar barroquismos que soariam artificiais e deslocados no contexto geral.

\section{A tradução de raimundo nonato barbosa de carvalho (2010)}

Contempla, à beira, os seus olhos, estrelas gêmeas, a cabeleira digna de Apolo e de Baco, a face impúbere, o pescoço ebúrneo, a grácil boca e o rubor à nívea candura mesclado; e admira tudo aquilo que o torna admirável. Sem o saber, deseja a si mesmo e se louva, cortejando, corteja-se; incendeia e arde.

Quantos beijos irados deu na falaz fonte!

Quantas vezes querendo abraçar a visão, na água os braços mergulhava achando nada!

Raimundo de Carvalho opta pelo tradicional dodecassílabo com acento obrigatório na sexta e na décima segunda sílabas (o alexandrino). É o mesmo verso que Haroldo de Campos adotou em suas traduções de Homero e de Ovídio. O tradutor não dá grande atenção ao plano visual.

No verso 423, Raimundo Carvalho mantém as palavras do original, mas desloca o mixtum para a posição final do verso, o que poderia se justificar argumentando-se que essa é uma posição de destaque no verso português. No entanto, ele não mantém a mistura dos

\footnotetext{
${ }^{15}$ Benjamin (2001).
} 
elementos: coloca o mixtum ruborem nos extremos do verso, unindo o niueo candore ao centro. No verso seguinte, corrompe inteiramente o "modo de visar" do original, modificandolhe inclusive o sentido ou, no mínimo, perdendo a ambiguidade ali presente. Perde o espelhamento icônico: no seu verso, "tudo" espelharia "torna".

O seu verso 427, além de não reproduzir o verso áureo, padece de uma gralha tradutória: escorrega na armadilha de um falso cognato, traduzindo o adjetivo inrita por “irados". Por fim, nos dois versos finais são desfeitas as mimeses.

Em resumo, podemos dizer que sua tradução pertence à mesma tendência explanadora que encontramos na tradução em prosa de David Gomes Jardim Jr. (o que transparece sobretudo na busca da manutenção de uma sintaxe simples), porém, com o acréscimo da metrificação.

\section{Nossa PROPOSTA DE TRADUÇÃo}

O latim, sendo uma língua sintética, possibilita uma ordem de palavras bastante livre. O português, entretanto, assim como as outras línguas neolatinas, perdeu essa característica, de modo que a definição das funções sintáticas das palavras passou a depender bastante de sua ordem na frase. Sendo a ordem das palavras fator definidor, é natural que ela tenha se tornado muito mais presa em português do que era na sua língua-mãe. É isso que gera a grande dificuldade que, junto a outros fatores, faz com que até hoje os tradutores tenham dificuldade com esses recursos de elocutio em suas traduções.

Em nossa tradução, buscamos explorar as possibilidades de concordância nominal da língua portuguesa (de número e de gênero) para compensar o melhor possível a perda da concordância de caso e para tornar um pouco mais livre a ordem das palavras em português, pelo menos no que se refere ao jogo de concordância entre adjetivos e seus respectivos substantivos. Tradutores do século XIX, como Francisco Xavier Pinheiro (Divina Comédia) e Odorico Mendes (tradutor de Homero e Virgílio) já haviam explorado ricamente essas possibilidades (além da concordância verbal) com diversas finalidades. ${ }^{16}$

As tentativas de reprodução das figuras de elocutio podem, por vezes, gerar hipérbatos no texto português. Isso não deve causar grande estranhamento, já que esse não é um recurso alheio a nossa tradição poética, sendo um dos usos característicos da nossa poesia barroca e romântica. Ao contrário do que ocorreu com a língua francesa ${ }^{17}$ e apesar da reação neoclássica

\footnotetext{
${ }^{16}$ Conferir as recentes edições das traduções de Odorico Mendes comentadas pelo Grupo de Trabalho Odorico Mendes, da Unicamp: em muitos passos os comentadores chamam a nossa atenção para algum recurso de elocutio preservado na tradução do maranhense.

${ }^{17}$ Para se ter uma imagem do quanto a língua francesa tornou-se mais conservadora com a ordem direta das palavras do que a língua portuguesa, confira as informações aportadas por Berman (2007) a respeito da recepção da Énéide de Pierre Klossowski em 1964.
} 
ao "exagero" barroco, na língua portuguesa, ${ }^{18}$ a possibilidade de uma certa variabilidade continuou sempre presente, ainda que limitada, na ordem das palavras, sobretudo em poesia (os dois tradutores citados acima são exemplos disso).

Para preservar efeitos funcionais de elocutio e estender um pouco mais as nossas liberdades, também exploramos as possibilidades de aposição da língua portuguesa. Quanto ao verso, na tentativa de sugerir a agilidade do ritmo ovidiano, nos esforçamos por criar dodecassílabos com ritmo binário, procurando fazer com que todas as sílabas pares dos versos sejam acentuadas:

Prostrado admira gêmeos astros, lumes ${ }^{19}$ seus,

De Baco dignas vê, também de Febo, as crinas,

Um colo de marfim, e bela face imberbe;

Que boca! E à neve misto, ao candor, rubor.

Tudo ele admira, sendo admirado ele mesmo:

Louco, anelou a si, um louva e é louvado,

Demanda e é a demanda, acende e junto arde.

Quantos beijos na fonte (todos vãos) falaz!

À água, ao reflexo lança os braços, ao pescoço

apreensivos, nela nunca se encontrando.

$\mathrm{Na}$ tradução do verso 423, conseguimos manter toda a ordem das palavras. A repetição da preposição "a" regendo "neve" e "candor" garante a relação entre os dois termos com algo semelhante a uma concordância de caso. A interposição de "ao candor", como aposto, entre o predicativo (misto) e o sujeito (rubor) não atrapalha a percepção da

\footnotetext{
${ }^{18}$ Segundo Rosenfeld e Guinsburg (1985), a França não teve um barroco: enquanto o barroco estava no auge na península ibérica, no século de ouro da literatura espanhola, a França vivia o classicismo de Corneille e Racine.

${ }^{19}$ A tradução de lumina ilustra por que Berman (2007, p. 19) nos diz que a tradução pode prescindir de teoria, mas não de reflexão. Poderíamos ter traduzido o termo por "olhos", como o fazem a maioria dos tradutores, sem que a métrica sofresse nenhuma alteração: os dicionários trazem sempre essa acepção para o termo. Entretanto, somos obrigados a refletir até que ponto trata-se de uma metáfora fossilizada, gramaticalizada a ponto de deixar de ser sentida como tal e passar a ser sentida meramente como polissemia ou até que ponto ela permanece uma metáfora viva, sentida como tal, como um desvio do significado padrão. Decidimo-nos por "lumes", pois claramente Ovídio faz uma brincadeira com palavras pertencentes a um mesmo campo semântico (sidus e lumina). Propércio (II, 3,14 ) nos oferece a oportunidade de contrastar o efeito causado pelos dois termos (lumina e oculi): non oculi, geminae, sidera nostra, faces: "nem seus olhos, meus astros, fachos gêmeos", na tradução de Flores (2014). Propércio precisou do intermédio do substantivo fax ("tocha", "facho") para acrescentar o sema "fonte de luz" a oculi, garantindo sua relação com sidera. Esse lugar-comum aparece ainda no Corpus Tibullianum: no sexto verso da primeira elegia atribuída a Sulpícia temos "accendit geminas lampadas acer Amor" ("gêmeas tochas, acerbo Amor acende", na tradução de Oliva Neto, 2016). O fato de cada um dos três exemplos usar termos diferentes para relacionar olhos com o sema fonte de luz, indica claramente que a metáfora permanecia viva.
} 
relação sintática entre os termos. A palavra-chave, "misto", permanece na posição central e os elementos permanecem entrelaçados, ainda que a relação entre niueo e candore tenha ficado mais frouxa do que no original por não constituírem um mesmo sintagma. Mantivemos também a ordem dos elementos (brancos no centro, vermelhos nos extremos do verso): vermelho (boca) - branco (neve) - branco (candor) - vermelho (rubor).

Ao traduzir o verso 424, tivemos o cuidado de manter o espelhamento do original, que mimetiza a cena que descreve, o âmago de todo esse trecho:

\section{Cunctaque miratur quibus est admirabilis ipse}

Tudo ele admira, sendo admirado ele mesmo

De um lado temos "tudo ele", do outro, perfeitamente espelhado, "ele mesmo", de um lado o agente ("admira"), do outro, o paciente ("admirado"), tudo isso com o verbo "ser" (o espelho d'água) no centro, reforçando a identidade entre os dois. Aquilo que o faz admirável e que foi antes perdição de outros, é agora sua própria perdição. Eis o erro de Narciso: sempre ele nos dois lados da água, tem-se por tudo, fecha-se sobre si mesmo e esquece-se de tudo que é "outro".

Para manter a estrutura de verso áureo no verso 427, recorremos à aposição:

inrita fallaci quotiens dedit oscula fonti, quantos beijos na fonte (todos vãos) falaz.

Não conseguimos manter a interessante ordem do original, com os dois adjetivos (um no acusativo plural, outro no dativo singular, portanto, se referindo cada qual a uma coisa diferente) aparecendo imediatamente e deixando o leitor na expectativa: que coisas são vãs? o que é falaz? Assim, nossa tradução desse verso é fiel apenas na superfície do sentido. Tentamos compensar essa perda e manter ao menos a densidade poética do verso, aportando grande atenção às suas potencialidades visuais. Os beijos vãos estão, de fato, na fonte falaz e ela é turbada quando os lábios encostam, sumindo a imagem fugaz. O verso apresenta ainda iconicidade da sequência temporal das ações: o impulso ("vou beijar!"); o face-a-face (encara a imagem clara na fonte extasiado, aproximando-se para beijá-la); o beijála e perceber que são vãos os beijos; por fim, a reação contra a fonte: "falaz!". Se quisermos levar a iconicidade ainda mais longe, percebamos que os parênteses reproduzem visualmente os círculos que se geram na água (bem no meio da fonte falaz) com o toque de sua boca e que turvam a imagem amada, como esse aposto turva o sentido da frase.

Por fim, os versos 428 e 429 nos oferecem alguma dificuldade. Ovídio explora as possibilidades de concordância nominal da língua latina (número, gênero e caso) para poder quebrar três diferentes sintagmas e, misturando-os, efetuar uma dupla mimese de conteúdo. Ainda que apareçam misturados nos versos, o leitor latino perceberá que uisum (adj. neutro, acusativo, singular) só poderá concordar com collum (subst. neutro, acusativo, singular), ao passo que captantia (adj. neutro, acusativo, plural) somente poderá concordar com bracchia (subst. neutro, acusativo, plural). O que difere os dois pares, separando que adjetivo concorda com que substantivo, é somente a concordância de número. Ora, em língua portuguesa não 
nos falta a concordância nominal de número, o que poderia nos fazer pensar que seria fácil traduzir o trecho. Vejamos como isso funcionaria numa tradução literal:

em médias (quantas vez̧es, ao visto, captantes, ao pescoço, os braços estendeu) águas e não se agarrou nelas.

Primeiramente, foquemos nossa atenção no trecho entre parênteses: ele não é de modo algum ilegível. A oposição singular-plural garante que relacionemos corretamente os termos e a repetição da preposição "a” (sugerindo uma concordância de caso) torna ainda mais marcada a relação entre "visto" e "pescoço". A mimese interna pode, portanto, ser preservada sem grandes dificuldades. É apenas naquilo que está fora dos parênteses, na mimese externa, que encontramos algum estranhamento. No original temos in mediis aquis: a concordância de caso é, aqui, fundamental, pois mediis e aquis estão separados por toda uma frase e o que garante que o leitor vai interligá-los com facilidade é o fato de que ambos são os únicos termos que se encontram no ablativo plural. ${ }^{20}$ Não temos em português uma construção que ecoe esse "modo de visar" do latim ("em médias águas"). Podemos resolver a dificuldade, deslocando a anáfora (in illis) para o início da segunda oração:

Nas águas (quantas vezes, ao visto, captantes, ao pescoço, os braços mergulhou) nelas nunca se agarrando.

Entretanto, se quisermos levar ainda mais longe o jogo de Ovídio, podemos ver nesses versos, sugerido pela sequência das palavras, o fato de que por mais que Narciso tente agarrá-la (captantia, deprendit), a água (mediis, aquis, illis), "spem sine corpore”, sempre lhe escapa:

in mediis quotiens uisum captantia collum

bracchia mersit aquis nec se deprendit in illis!

Nossa solução final, em verso dodecassílabo, deslocando a anáfora para o meio do segundo verso (cercada entre "apreensivos" e "abraçando") para compensar a impossibilidade de usar a concordância substantivo-adjetivo, perde esse interessante efeito:

À água, ao reflexo lança os braços, ao pescoço

apreensivos, NELA nunca se abraçando.

\section{ConsideraÇões finaIs}

Longe de se dever meramente à conveniência métrica, o caráter fragmentário da sintaxe poética latina corresponde com muita frequência às elaboradas figuras retóricas de elocutio de que estamos tratando, ao trabalho com a visualidade do poema (a mimese de conteúdo), com finalidades poéticas rebuscadas: não são simplesmente aceitas por um poeta contrariado, mas de fato arduamente (re)buscadas por ele.

${ }^{20}$ Desde que anunciado, no início do verso 428, o adjetivo mediis, o leitor permanece com uma estrutura aberta, suspensa, aguardando o referente daquele adjetivo, que surge finalmente em aquis. 
Nossa análise das diferentes traduções desse mesmo trecho em língua portuguesa indica que nenhum dos tradutores deu conta daqueles recursos. Isto é, em todo o corpus das traduções que encontramos, cobrindo quatro séculos e um variado leque de concepções de tradução (desde as mais acadêmicas até as mais criativas e livres), não há nenhum tradutor que tenha praticado o que Berman (2007, p. 26) ${ }^{21}$ qualifica de tradução "ética", aquela que, em contraposição à tradução etnocêntrica, respeita a letra do original, esquivando-se das tendências deformadoras e conservando seus aspectos significantes. Com isso, vemos confirmada, num caso concreto, a leitura que o teórico francês faz da história da tradução no Ocidente: "sua figura dominante é culturalmente etnocêntrica, literariamente hipertextual e filosoficamente platônica” (Berman, 2007, p. 26).

Conforme temos observado em grande quantidade de edições recentes, bilíngues, de autores latinos, muitos tradutores "poéticos", principalmente quando se trata de poemas narrativos longos, apenas acrescentam às suas traduções (em comparação com as traduções em prosa) a metrificação. Isso é apenas um aspecto mais geral da macroestrutura do poema. Mas é evidente que não é só nisso que reside a poeticidade dessas narrativas: é preciso olhar mais de perto, nas suas microestruturas, no trabalho com as palavras e os jogos de significado, pois é aí que o leitor encontrará o prazer estético que busca, e é isso que o segurará e o fará continuar a leitura até o fim.

Quando vão além da metrificação, nossos tradutores chegam no máximo a tentar reproduzir uma ou outra aliteração ou algum outro recurso do plano da expressão sonora e se contentam com essa relativa homomorfia, que se limita ao plano sonoro da poesia. ${ }^{22}$ Porém, como vimos, o plano da disposição visual não é de somenos importância na tradição da poesia latina. E isso tem sido negligenciado, o que não se deve, certamente, à falta de estudos sobre as diferenças entre a poesia oral e a escrita, ${ }^{23}$ ou sobre a recorrência de recursos visuais nos poetas latinos (que, ainda que esparsamente, têm começado a aparecer). ${ }^{24}$

\footnotetext{
${ }^{21}$ Veja também o capítulo $A$ ética da tradução (Berman, 2007, p. 63-71).

${ }^{22}$ Mesmo essa homomorfia do plano sonoro é bastante relativa. A tradução de hexâmetros e pentâmetros respectivamente por dodecassílabos e decassílabos portugueses, cuja rítmica é gerada exclusivamente pelas diferenças acentuais, não pode passar de correspondência funcional (para uma exposição dos conceitos de correspondência formal e funcional, cf. Britto, 2006), tendo fracassado todas as tentativas de reprodução formal dos versos gregos (sendo a mais célebre a do maranhense Carlos Alberto Nunes, que traduziu os hexâmetros por versos de dezesseis sílabas com uma regularidade rítmica ternária totalmente estranha à rica variedade do verso grego e do latino). E nem só à forma sonora ou visual se limita o trabalho poético nesses textos latinos: há diversos jogos semânticos que muitas vezes passam impercebidos pelos tradutores apressados. Quanto a isso, mesmo as traduções em prosa costumam pecar, e cabe a discussão: qual o limite entre forma e conteúdo em poesia?

${ }^{23}$ Confira seleção bibliográfica em Thomas (2005).

${ }^{24}$ Atualmente, o estudo mais completo sobre o tema é Martins (2016), que estuda as funcionalidades da elocução nas elegias eróticas de Tibulo. As traduções de Odorico Mendes foram pioneiras nesse sentido, embora não muito regularmente. Elas têm sido revalorizadas desde fins do século XX por Haroldo de Campos. Suas traduções das Bucólicas e da Eneida foram privilegiadas com edições ricamente
} 
Tampouco essa negligência com o plano visual da poesia latina pode ser explicada por ausência de tradição visual na poesia lusófona. Tanto em Portugal quanto no Brasil, tanto no passado mais remoto quanto no presente mais vivo (como demonstra Ana Hatherly ${ }^{25}$ e como rápido se torna evidente a qualquer conhecedor das nossas literaturas), temos uma constante e sempre viva tradição de exploração de recursos visuais em poesia, o que facilita a correspondência funcional de soluções tradutórias, que não nos pareceriam de todo estranhas.

A exclusividade com que o som tem recebido a atenção daqueles tradutores que, se contrapondo à tradução filológica que dominou todo o século $\mathrm{XX},{ }^{26}$ têm tido um maior cuidado com a forma e o significante ao traduzir poesia acontece à revelia do que nos diz Benjamin (2001 [1923]), que, quer diretamente, quer através dos irmãos Campos, tem sido também um dos teorizadores mais influentes no campo:

A verdadeira tradução é transparente, não encobre o original, não o tira da luz [...] Esse efeito é obtido, sobretudo, por uma literalidade na transposição da sintaxe, sendo ela que justamente demonstra ser a palavra - e não a frase - o elemento originário do tradutor. Pois a frase constitui o muro que se ergue diante da língua do original e a literalidade, sua arcada.

Seguindo os passos de Benjamin, Antoine Berman (teórico cuja presença nos nossos cursos universitários é patenteada pela frequência com que é citado nos artigos sobre tradução) destaca a importância do trabalho com a sintaxe, dedicando toda a parte final do seu livro mais influente no Brasil, O albergue do longínquo (2007), ao estudo da polêmica tradução francesa da Eneida por Klossowski (1964). Entretanto, quando analisa trechos da célebre tradução, apenas aponta que Klossowski conseguiu "passar uma impressão de literalidade [...] sem ser de fato literal” ao “implantar em francês o caráter 'fragmentado' da sintaxe latina", e conclui que o que deve ser traduzido "é o sistema global das inversões, rejeições, deslocamentos, e não suas distribuições factuais ao longo dos versos da Eneida". ${ }^{27}$

Curiosamente, nem mesmo Haroldo de Campos, o poeta concreto e tradutor cuidadoso de poesia chinesa, parece ter plena consciência da funcionalidade muitas vezes presente nesses jogos de elocutio latinos. Ao falar da mesma Énéide de Pierre Klossowski, ele apenas nos diz, reproduzindo Berman, que:

comentadas pelo Grupo de Trabalho Odorico Mendes, da UNICAMP (coordenado pelo professor Paulo Sérgio Vasconcellos) que valoriza, entre outros, esse aspecto das traduções do maranhense no comentário.

${ }^{25}$ Cf. Hatherly (1977 e 1983).

${ }^{26}$ Confira as palavras iniciais de Campos (1977, p.109): "Naturalmente essa tradução não é para filólogos ensimesmados em suas especialidades como em tumbas de chumbo, indesejosos de comércio com os vivos. É uma tradução para os que se interessam por um texto de poesia como poesia, e não como pretexto para considerações sapientes em torno do autor e de sua era"

${ }^{27}$ No original, o trecho todo vem destacado em itálico. O destaque em negrito é nosso. 
se rebela contra as tradições gramaticais do país de Malherbe, no empenho de reconfigurar o "aspecto deslocado" da sintaxe latina, num gesto antinormativo que o teórico da tradução Antoine Berman [...] faz corresponder a uma crise do "etnocentrismo em cultura". 28

Augusto e Haroldo de Campos são provavelmente as autoridades mais influentes no campo da tradução no Brasil. Os irmãos paulistanos elevaram o nível das traduções poéticas no país ao defender (na esteira de Berman e Benjamin, que eles citam não poucas vezes) o cuidado maior com o significante (embora sem desprezar a forma do conteúdo). ${ }^{29}$ Entretanto, apesar de terem ao longo de toda a sua carreira como criadores de poesia trabalhado com a visualidade (disposição dos elementos na página, cores, tipos de fontes), na sua teorização e na sua prática tradutória permaneceram quase sempre alheios a esses elementos, dando maior ênfase, no que diz respeito ao significante da poesia clássica latina, ao trabalho no âmbito da expressão sonora dos poemas, trabalho no qual chegaram à excelência.

Como indica o próprio fato de apresentarmos aqui nossa tentativa de demonstrar a possibilidade de solução ao menos parcial desse problema, e de conciliar as múltiplas demandas do tradutor de poesia latina hoje, não fazemos essas críticas para negar a validade e a necessidade de darmos esse passo à frente, deixando para trás as incompletas (pois de antemão resignadas com a perda de um elemento importantíssimo do texto-fonte) traduções em prosa. Não podemos resistir ao desejo, nem podemos nos esquivar do dever, de comunicar as belezas que encontramos na fonte latina a um público mais amplo. No entanto, parece que estamos ainda num momento muito incipiente desse novo trajeto e esse é o momento para reavaliarmos nosso ponto de partida, nossa leitura do texto-fonte. Revela-se obviamente imprescindível que tenhamos sempre em vista a forma do original ${ }^{30}$ e os estudos sobre sua leitura e que, assim, não trabalhemos às cegas. Pois, como nos diz Benjamin, é lá, no original, que encontraremos a forma que deveremos reproduzir na nossa tradução e se partirmos de uma leitura deficiente dessa forma, nossa tradução será necessariamente deficiente, pois, lembrando a autopsicografia de Pessoa, a nossa tradução nunca será a tradução do texto original (como um leitor ingênuo poderia pensar), mas, inevitavelmente, a tentativa de tradução da nossa leitura do texto original.

\footnotetext{
${ }^{28}$ Campos (1992, p. 13).

${ }^{29}$ Campos (1994).

${ }^{30}$ Benjamin (2001, p. 205): "A tradução é forma. Para apreendê-la como tal, é preciso retornar ao original. Pois nele reside a lei dessa forma".
} 


\section{REFERÊNCIAS}

ALBERTO, Paulo Farmhouse. Introdução. In: OVÍDIO. Metamorfoses. Tradução de Paulo Farmhouse Alberto. Lisboa: Livros Cotovia, 2007, p. 11-32.

BENJAMIN, Walter. A tarefa do tradutor. Tradução Susana Kampff Lages. In: HEIDERMANN, Werner (org.). Clássicos da teoria da tradução. 2.ed. Revista e ampliada. Florianópolis: UFSC, 2001, p. 202-229.

BERMAN, Antoine. A tradução e a letra ou $O$ albergue do longinquo. Tradução de Marie-Hélène Catherine Torres, Mauri Furlan e Andreia Guerini. Rio de Janeiro: 7Letras, 2007.

BRITTO, Paulo Henriques. Correspondência formal e funcional em tradução poética. In: SOUZA, Marcelo, P.; et alii (org.). Sob o signo de Babel: literatura e poéticas da traducão. Vitória: Flor\&Cultura, 2006.

CAMPOS, Haroldo de. Píndaro hoje. In: A arte no horizonte do provável. São Paulo: Perspectiva, 1977, p. 109-119.

CAMPOS, Haroldo de. A morte de Narciso. In: Crisantempo: no espaço curvo nasce um. São Paulo: Perspectiva, 2004, p. 210-213.

CAMPOS, Haroldo de. A ira de Aquiles: Canto I da Ilíada de Homero. São Paulo: Nova Alexandria, 1994.

CAMPOS, Haroldo de. Odorico Mendes: o patriarca da transcriação. In: HOMERO. Odisseia. Edição da tradução de Odorico Mendes preparada por Antônio Medina Rodrigues. São Paulo: Edusp, 1992.

CARVALHO, Raimundo Nonato Barbosa de. Metamorfoses em tradução. São Paulo: USP, 2010.

CASTILHO, António Feliciano de. Theatro de Molière, terceira tentativa - As sabichonas, comédia em 5 atos: versão libérrima. Lisboa: Typographia da Real Academia de Ciências de Lisboa, 1872.

FLORES, G. Gontijo (org. e trad.). Elegias de Sexto Propércio. Belo Horizonte: Ed. Autêntica, 2014.

GUERINI, Andreia; COSTA, Walter Carlos. Entrevista com João Angelo Oliva Neto. Cadernos de Tradução, v. 1, n. 25, p. 259-278, 2010.

HATHERLY, Ana. A experiência do prodígio. Bases teóricas e antologia de textos visuais portugueses dos séculos XVII e XVIII. Lisboa: Imprensa Nacional Casa da Moeda, 1983.

HATHERLY, Ana. Visualidade do texto. Uma tendência universalista da poesia portuguesa. Revista Colóquio/Letras, n. 35, p. 5-17, 1977.

HEIDERMANN, Werner (org.). Clássicos da teoria da tradução. 2.ed. Revista e ampliada. Florianópolis: UFSC, 2001.

HOMERO. Iliada. Tradução de Frederico Lourenço. São Paulo: Companhia das Letras, 2014. 
HOMERO. Odisseia. Tradução de Frederico Lourenço. São Paulo: Companhia das Letras, 2014.

LUCRÉCIO. Da Natureza das Coisas. Tradução de Luís Manuel Gaspar Cerqueira. Lisboa: Relógio d'água, 2015.

MARTINS, Maria Helena Aguiar. A elocução do amor em Tibulo. Dissertação (Mestrado em Literatura Comparada) - Programa de Pós-Graduação em Letras, Universidade Federal do Ceará, Fortaleza, 2016.

OVÍDIO. Amores \& Arte de Amar. Tradução, introduções e notas de Carlos Ascenso André; Prefácio e apêndices de Peter Green. São Paulo: Penguin-Companhia das Letras, 2011.

OVÍDIO. Os quatro primeiros livros da Metamorphose, de P. Ovidio Nasaõ, poeta romano. Traduzidos em verso solto portuguez por Almeno. Lisboa: Typografia Lacerdina, 1805.

OVÍDIO. As Metamorphóses de Publio Ovidio Nasão. Poema em quinze livros vertido em portuguez por Antonio Feliciano de Castilho. Lisboa: Imprensa Nacional, 1841.

OVÍDIO. Metamorfoses. Tradução de David Gomes Jardim Jr. Rio de Janeiro: Ediouro, 1983.

OVÍDIO. Metamorfoses. Tradução de Paulo Farmhouse Alberto. Lisboa: Livros Cotovia, 2007.

OVÍDIO. Os Fastos. Introdução, tradução e notas de Márcio Meirelles Gouvêa Jr. Belo Horizonte: Autêntica, 2015.

PREDEBON, Aristóteles Angheben. Edição do manuscrito e estudo das Metamorfoses de Ovídio traduzidas por Francisco José Freire. Tese (Doutorado em Letras Clássicas) - Programa de PósGraduação em Letras Clássicas e Vernáculas da Faculdade de Filosofia, Letras e Ciências Humanas da Universidade de São Paulo, São Paulo, 2006.

ROSENFELD, Anatole; GUINSBURG, J. Romantismo e Classicismo. In: GUINSBURG, J. (org). O Romantismo. 2.ed. São Paulo: Perspectiva, 1985.

SCHLEIERMACHER, Friedrich. Sobre os diferentes métodos de tradução. Tradução de Celso R. Braida. In: HEIDERMANN, Werner (org.) Clássicos da teoria da tradução. 2. ed. revista e ampliada. Florianópolis: UFSC, 2001, p. 38-101.

THOMAS, Rosalind. Letramento e oralidade na Grécia Antiga. Tradução de Raul Fiker. São Paulo: Odysseus, 2005.

VASCONCELLOS, Paulo Sérgio. A tradução poética e os Estudos Clássicos no Brasil hoje: algumas considerações. Scientia Traductionis, n.10, p.68-79, 2011.

VIRGILE. L'Énéide. Texte établi par Henri Goelzer et traduit par André Bellessort. Paris: Belles Lettres, 1961. 